\title{
25 Research Square

\section{A Structural Equation Modeling of the Wealth and Welfare Components in Iranian Households: Rural and Urban Dichotomies}

\section{Sediqe Shafiei}

Shahid Beheshti University of Medical Sciences School of Dentistry

\section{Sareh Shakerian}

Shahid Beheshti University of Medical Sciences School of Management and Medical Education

\section{Shahram Yazdani}

Shahid Beheshti University of Medical Sciences School of Management and Medical Education

\section{Mohammad-Pooyan Jadidfard}

Shahid Beheshti University of Medical Sciences School of Dentistry

\section{A. Hamid Zafarmand ( $\nabla$ h.zafarmand@sbmu.ac.ir)}

Shahid Beheshti University of Medical Sciences School of Dentistry https://orcid.org/0000-0002-62337018

\section{Research}

Keywords: Welfare, Wealth, Rural, Urban, Poverty, Socioeconomic Status, Confirmatory Factor Analysis, Structured Equation Modeling, deprivation, Iran

Posted Date: October 15th, 2020

DOl: https://doi.org/10.21203/rs.3.rs-89817/v1

License: (c) (1) This work is licensed under a Creative Commons Attribution 4.0 International License. Read Full License 


\section{Abstract}

Background: Increasing social welfare and reducing poverty are to ensure the well-being of all classes of a society. Cities and villages are distinguished by cultural and economic disparities. The purpose of this study was to develop and present a comprehensive model on welfare and wealth components and their relationship with each other, as well as determining the contributing factors and variables affecting them by presenting a comprehensive model.

Methods: The components of wealth and welfare were determined based on the national data comprising 19261 rural and 18701 urban household participants. Initially, the conceptual model was drawn. Later, observed and latent variables of the model were analyzed and tested using AMOS software, in two exploratory and confirmatory factor analyses. Finally, the Structural Equation Modeling was used to analyze the data and investigate the causal relationship of latent variables.

Results: The findings showed that the factors generating wealth in the urban initiate from education and lead to employment and then into income and ultimately provide wealth and welfare. Plus, there is no separation between the concept of welfare and wealth in urban society. However, land ownership is the prerequisite for wealth and welfare issues in a rural community. Moreover, wealth and welfare are two distinct phenomena in rural areas.

Conclusions: The results of this study would provide the clear hints for effective policy making to resolve deprivation and poverty in Iranian rural and urban populations, prioritizing education for urban and land ownership for rural areas.

\section{Introduction}

Increasing social welfare and reducing poverty are among the main goals of any country's economic developmental plan. One of the main tasks of rulers and economic policy makers is to ensure the wellbeing of all classes of a society. Throughout the history, poverty and injustice have always been a concern for human societies. Therefore, the issues of justice, equality, and social welfare, even before being an economic issue, are a socio-political subject. (1)

Generally, welfare is defined as the governmental task to be provided for the citizens of a society which includes all members, regardless of the level of income. Accommodating basic needs for all society members is the least expectation in social welfare. These needs include food, housing, literacy, health, and employment opportunities. In fact, as a definite mission, governments are responsible for provision of equal access to the above basic needs. (2)

It should be noted that wealth, in general, is considered as one of the influential factors in promotion of the level of family welfare. Although wealth and welfare implicate completely two different meanings, most economists believe that there is a positive association between them. 
In general, experts believe that production of wealth includes: (3)

1. Access to income generating opportunities.

2. Income generating capabilities.

3. Security for income generation.

4. Power.

Cities and villages, in addition to complex dialectical relationships, are distinguished by cultural and economic disparities. The fact is that, from the economic point of view, rural dwellers earn higher income than residents living in urban areas. This difference is less noticeable in developed countries than in developing nations. (4) According to most researchers and experts, the development of agricultural industry is recognized as the main economic lever for rural households. For that reason, land is regarded as the vital economic resource. Experts, therefore; adhere to the concept that the solution to the issue of global poverty is to reinforce agricultural facilities and land ownership for farmers. (5)

Gardes et al. (6) in his study of poverty, inequality, and income mobility in Ecuador concluded that despite the decline in poverty rates during the years $2000-2009$, there is still a noticeable difference between rural and urban areas. In other word, poverty and inequality still remain as a critical issue in rural areas.

Many developing countries are now facing the widespread inequalities between rural and urban communities. Based upon the findings of an investigation in Iran, the number of poor households in rural areas is more than of urban households. In addition, poor rural households are far poorer than of urban households. (7) Another study showed that income distribution in rural areas of Iran is more unbalanced than of urban areas. (8)

The Government of Islamic Republic of Iran has taken numerous measures to implement social justice in the country. For example, proposing the bill of "Economic Organizing Plan" to the parliament in 1998 was a strong step taken for economic balance. The Act of establishing the Ministry of Welfare and Social Security in 2004 was the other action in this regard. (9 \& 10) Another study has shown that despite of increasing endeavor for convergence of Iran's economy towards the world economy to reduce the poverty gap among urban households, yet; it has presented unpleasing consequences on rural areas. (11) This is indicative of the fact that the concepts introduced in the global context are not necessarily generalizable to all countries.

Unfortunately, in some rural areas of Iran, the less productive traditional agriculture is still visible. Thus, it seems that increasing productivity by means of modern technology should be considered as one of the important targets for elimination of deprivation and poverty in rural communities. (12)

The purpose of this study was to develop a comprehensive model on welfare and wealth components and their relationship with each other, as well as determining the contributing factors and variables affecting on them, in separate for urban and rura/ households. 


\section{Method And Materials}

For the purpose of this study, our detection was based on the data from the National Statistics Center of Iran (NSCl), in 2017. The data was classified as urban and rural households, separately. Participants in this social referendum included 19261 rural households and 18701 urban households.

In this study, a theoretical model was initially designed based on the welfare and wealth components and their inter-relation to each other, as indicated in the literature. (2) The model also defines the contributing factors to production of wealth. Then, a conceptual framework of the model was developed for further analysis based on the $\mathrm{NSCl}$ data.

In the initial theoretical model, welfare components were extracted from the critical review and obtained from the previous study on SES measurement model. (13) That study was based upon various health studies in Iran over a 10-year period, from July 2007 to 2017 . These components include 15 items:

1. Household size.

2. Education of head of household.

3. Occupation of head of household.

4. Household monthly income.

5. Type of school that children attended. (public/private)

6. House ownership.

7. Local value of residence.

8. Number of rooms in the house.

9. House area.

10. Personal computer/ laptop.

11. Smart cell phone.

12. Three-dimensional television.

13. Dishwasher.

14. Microwave.

15. Car ownership.

It should be noted that some factors were excluded from the initial theoretical model, due to the lack of data in the $\mathrm{NSCl}$ annual report. Also, meat and fruit items were redirected to the nutrition section of the conceptual model. This was due to an existing comprehensive study on economic inequality in the fields of knowledge, attitude, and practice on nutrition for Iranian households. That study substantiated a strong relation between SES level and meat and fruit consumption. (14) It should be emphasized that the number of households is a determinative variable for estimating per capita household expenditure. Collectively, our conceptual model was modified according to the above mentioned factors. (Diagram 1) Finally, this was the basis for examining and analyzing the conceptual model regarding to NSCI 2017 data file, which was differentiated by the urban and rural households.

\section{Data Analysis}


In this study, "Structured Equation Modeling" (SEM) method was used to analyze the data and to investigate the causal relationship of latent variables (for example: welfare) with measurable observed variables (for example: home ownership type). The SEM method is a new statistical tool that, in addition to current statistical methods like: variance analysis, regression, and path analysis, provides the possibility to include confirmatory factor analysis, confirmatory composite analysis, path analysis, partial least squares path modeling, and latent growth modeling. (15) Normality test for data and model fit were evaluated and validated at each step. Model fit indices presented acceptable values and the final model were recognized with highly validity. (Table 1 )

Table 1

AMOS Goodness-of-fit measures of the Model.

\section{Measures of Fitness}

\begin{tabular}{|lll|}
\hline Coefficient/Index & Rural & Urban \\
\hline Chi-square & P value $=0.000$ & P value $=0.000$ \\
\hline RMSEA $_{1}$ & 0.072 & 0.051 \\
\hline $\mathrm{NFI}_{2}$ & 0.908 & 0.963 \\
\hline $\mathrm{AGFI}_{3}$ & 0.937 & 0.968 \\
\hline $\mathrm{GFI}_{4}$ & 963 & 982 \\
\hline $\begin{array}{l}\text { (1. Root mean square error of approximation, 2. Normed-Fit Index, 3. Adjusted Goodness-of-Fit Index, } \\
\text { and 4. Goodness-of-Fit Index) }\end{array}$ & \\
\hline
\end{tabular}

Then, the latent and observed variables of the model were analyzed and tested using AMOS and SPSS (version \#21) statistic softwares in two exploratory and confirmatory steps. (Diagram 2) The next step was, creating the measurement and structural model to examine the relationship between the factors and their level of contribution to the model. Normality test for data and model fit were evaluated and validated at each step. The guide was that the elements with value of less than 0.3 of factor loadings were omitted since it was considered as a weak relation.

Final models were edited based on the model fit indices; and the model correction suggestions were specified into two groups of rural and urban population. Regression coefficients and correlation coefficients between latent variables and main components of the study were also calculated. In addition, factor loadings of each observed variable, regression weight, and the contribution of each factor to the explanation of the latent components were estimated and presented for final interpretation.

\section{Results}

The results of study are classified in 2 distinct rural and urban geographic areas. These are: 


\section{A: Rural Data (Diagram 3)}

Findings from Exploratory Factor Analysis for welfare components in rural data from Conceptual Research Model were approved with values greater than 0.4 in 3 fields: appropriate nutrition, appropriate home appliance, and appropriate housing. However, in the first and second Confirmatory Factor Analysis in the AMOS software, two welfare components of dishwasher and microwave variables in the home appliance section were not confirmed, due to factor loads of 0.23 and 0.15 respectively. Additionally, one welfare components in the housing section, the type of home variable with a factor load of 0.19 (less than $30 \%$ ) were disregarded. Therefore, these three welfare components were not qualified for the conceptual model.

All factor loading values were significant and were approved after second Confirmatory Factor Analysis. (P-value $\leq$ 0.001) As the model fit indices were at appropriate levels, the conceptual model of the research was therefore confirmed with respect to most of the principal component variables.

In the initial conceptual model of the factor leading to wealth production, education was not an effective factor in job creation. (0.15) Again, education did not have a significant impact on income generation either. (0.01) As a result, the level of education did not show to be a contributing factor in creation of an effective job for income generation in rura/households. However, education, occupation, household size, and income were confirmed as impact variables of the wealth component with factor loadings higher than 0.3 in the final model.

According to the conceptual model structured with this research, the relationship between wealth and welfare in rural households indicates a high correlation between these two components, with $96 \% \beta$ coefficient. Thus, wealth and welfare were identified as two separate subjects in the conceptual model and in the final structural model for rura/households.

\section{B. Urban Data (Diagram 4)}

The results of Exploratory Factor Analysis for welfare components in urban data from the Conceptual Research Model taken from NSCl data were confirmed with values above 0.4 in three domains: Appropriate Nutrition, Appropriate Home Appliance, and Appropriate Housing.

Moreover, these results were confirmed in first and second Confirmatory Factor Analysis with AMOS software for welfare components in the above three fields, and for all variables with factor loadings greater than 0.3. Yet, the type of home ownership with a factor loading of 0.25 did not prove to have a positive effect in the Appropriate Housing field. Model fit indices had acceptable values indicating high validity of the conceptual model.

In the initial conceptual model of the factors of wealth production and their relation with welfare components, education variable has proven to be an effective factor in job creation with regression coefficient of 0.64 . Consequently, job variable had a relatively definitive role on income generation with a value of 0.38 (P-value $\leq 0.001)$. Hence, education was confirmed to provide better access to various job 
opportunities for creating higher income for urban residents. In the final urban model, unlike the final rural model, wealth and welfare were NOT recognized as two separate components and did not have an acceptable fitness. In other word, in the urban household model, wealth and welfare were confirmed as a single category in the final structural model, based on the comprehensive data of the NSCl data source.

\section{Discussion}

This study was designed to provide a scientific model for the components of welfare and wealth in urban and rura/households based on data from NSCl. Also, identifying the relationship among these components to each other, the contributing level of factors, and the variables affecting them was the other purposes of the present investigation.

In the previous investigation SES items were detected for Iranian community. (13) Accordingly, SES items extracted from the previous study were added to the present conceptual model. After analysis, the welfare components model was confirmed in urban population. It is notable that the presented structural model proves the strong relationship between education and job as well as between job and income level. It should be emphasized that the factors generating wealth in a city initiate from education and then lead to employment. Consequently, employment facilitates income and ultimately it arranges wealth and welfare. In fact, in urban society there is no distinction between the concept of welfare and wealth, representing the two sides of the same coin.

The present study showed that the economic structure of rural society is quite different from that of urban society. After exploratory and confirmatory factor analysis for welfare components, it was found that wealth is the source of welfare in rural society. Therefore, in a rural community, a family with higher wealth earns higher income, may seek higher education for its younger members, and able to access more home facilities. In addition, the size of these families is noticeably larger. In the past, it was believed that family size reflects the pride and child-bearing ability is a privilege in the community. It was interesting to know that there is a similar condition, to some aspects, in Egypt and Ivory Coast rural communities. (16 \& 17) However, it seems that difference of interaction between wealth and welfare, in rural as opposed to urban social structure, may stems from cultural differences.

The results of this study showed that the urban community structure is in accordance with the proposed welfare and wealth model. It is, therefore; logic that in order to design poverty alleviation policies, it is better to institute on prerequisites of income generation in urban society, such as education. Conversely, such policies may not succeed in rural areas in the field of poverty alleviation, because of their defective causal mechanism. As such, in the countryside, policy makers should seek measures to consolidate land ownership concept rather than advocating education. Accordingly, land ownership is closely linked to agricultural production and consequently brings about income which in turn leads to wealth on the national level.

However, as a key factor, land has the pivotal role in wealth generation and economic equity, in a rural community. The results of a study on poverty and inequality in Tanzania also confirmed that human 
capital, land, and livestock as of the most important assets of rural households. (18) The UK Department for International Development states that land is a safe and secure livelihood asset for villagers. In addition, it is noteworthy to mention that it added that land is a necessary, but not always an absolute condition for poverty alleviation. (19) Another study conducted in Asian rural areas shows that rural poverty usually has an inverse relationship with the size of arable land. (20) Another study in Java endorses the fact that access to land is closely linked to access to capital, as well. (21)

As an emphasis, according to the Article \#30 and Article \#31 of the Iranian constitution, provision of free education is the task of government for citizens of the country. (22) Nonetheless, this does not imply that same policy can be implementable in rural areas as well as urban areas, for poverty alleviation. A national study on the distribution and severity of poverty concluded that poverty is a multidimensional phenomenon in rural areas. (23) In fact, the policy for poverty alleviation should trigger housing and education in such communities. But based upon the present investigation, land ownership has priority to the other factors. Obviously, this does not infer that state capitalism is a successful economic solution in a rural society.

Additionally, the entry of technology in the agricultural industry will undoubtedly increase the productivity, besides land ownership. The process of productivity will fail if the technology holder exploits the ownership of farmer. Another indicator which has a destructive role is inequity; a fact that has a tight link to poverty. This means the disproportionate distribution of ownership resources among farmers.

Plus, economic challenges are other indicators that may jeopardize income level of a villager. For instance, inflation is one of the major causes of decline in the purchasing-power of the low-income group. This economic indicator places this group in the vulnerable status with later consequences.

Unfortunately, the villagers are the main victims of unbridled inflation in the societies. In addition, lack of financial support can exacerbate this susceptibility condition. (24) It should be highlighted that governments have a definitive role in adoption of more equitable and targeted policies for the allocation and distribution of resources. These policies result in sustainable employment which settles a sustainable national economy.

\section{Conclusions}

The basis of wealth is different in rural area in comparison with in urban areas. This study emphasized that land ownership has the clear priority in the village, as opposed to of education in the city. It is worth mentioning that poverty deprivation policies should be based on the facilitation of above approach in the country's macroeconomic plans. Nevertheless, in urban areas, wealth and welfare are the two simultaneous effective dimensions of the urban economics. Finally, the results of this study may provide an effective solution to break the cycle of deprivation and poverty in rural and urban population with appropriate policy making.

\section{References}


1. Tanzi V. Globalization and the future of social protection. Scottish Journal of Political Economy. 2002; 49(1):116-127.

2. Van Ginneken W. Social security and the global socio-economic floor: Towards a human rights-based approach. Global Social Policy. 2009; 9(2):228-45.

3. UNESCO. Principal Regional Office for Asia and the Pacific. APPEAL training materials for continuing education personnel (ATL P - C E) Vol. V - Income-generating programs. (Asia-Pacific Programed of Education for All) Bangkok, 1992; 121 p. https://books.google.com/books/about/APPEAL_Training_Materials_for_Continuing.html

4. Charrier JB. Villes et campagnes: essai sur la diversité des rapports villes- campagnes à travers le monde. Masson; 1988.

5. Rigg J. Land, farming, livelihoods, and poverty: rethinking the links in the rural South. World Development. 2006; 34(1):180-202.

6. Canelas C. Poverty, Inequality, and Income Mobility: The Case of Ecuador: a Pseudo-panel Approach (Doctoral dissertation). 2010

7. Khalaj S, Yousefi A. Mapping the Incidence and Intensity of Multidimensional Poverty in Iran Urban and Rural Areas. The $\mathrm{J}$ of Spatial Planning. 2015;18(4):49-70.

8. Hoseini SM, Najafi SA. Income Distribution in Rural and Urban Areas of Iran (1363-1386). J of Agricultural Economics Research. 2009; 1(3):147-165.

9. Islamic Parliament Research Center of the Islamic Republic Of IRAN. Act of establishing the Ministry of Welfare and Social Security. [https://rc.majlis.ir/fa/report/show/728713], 2019.

10. Mowlaei M, Rahimi RZ. The Measurement of Subsistence Level in Iran's Urban and Rural Households during 1989-2013. J of Economic Research. 2018; 53(1):181-208.

11. Mousavi N, Bakhshoude M, Mohamadi H, Yazdani S, Taheri F. Evaluating the Effects of Globalization on Poverty Measures. Social Welfare Quarterly. 2007; 6(24):259-82.

12. Momeni F, Yousefi MG, Mobarak AS. Determinants of growth, labour productivity and poverty in rural areas of Iran. J of Rural Research. 2010; 1(1):99-120.

13. Shafiei S, Yazdani S, Jadidfard MP, Zafarmand AH. Measurement components of socioeconomic status in health-related studies in Iran. BMC Research Notes. 2019; 12(1):70.

14. Heshmat R, Salehi F, Qorbani M, Rostami M, Shafiee G, et al. Economic inequality in nutritional knowledge, attitude and practice of Iranian households: The NUTRI-KAP study. Med J of the I R of Iran. 2016; 30:426.

15. Kline, Rex. Principles and Practice of Structural Equation Modeling. Third Ed. 2011. Guilford. ISBN 978-1-60623-876-9.

16. Kouamé A, Schellekens J, Rabenoro M. Rural Development and Attitudes towards Family Size in Côte d'Ivoire. Population. 2002; 57(2):269-99.

17. Schutjer WA, Stokes CS, Poindexter JR. Farm size, land ownership, and fertility in rural Egypt. Land Economics. 1983; 59(4):393-403. 
18. Ferreira FH, Lugo MA. Multidimensional poverty analysis: Looking for a middle ground. The World Bank Research Observer. 2013; 28(2):220-35.

19. Quan J. Better livelihoods for poor people: the role of land policy. Discussion draft, Department for International Development (DFID), London. 2002.

[https://www.gov.uk/government/organisations/department-for-international-development]

20. Ali I, Pernia EM. Infrastructure and poverty reduction- what is the connection? ERD Policy Brief No. 13, Economics and Research Department, Manila, Philippines: Asian Development Bank. 2003 [https://think-asia.org/bitstream/handle/11540/613/pb013.pdf]

21. Breman J. Good times and bad times in rural Java: Case study of socio-economic dynamics in two villages towards the end of the twentieth century. Brill; 2002 Jan 1. Leiden: KITLV Press.

22. Constitution of the Islamic Republic of Iran. 1989

[https://www.wipo.int/edocs/lexdocs/laws/en/ir/ir001en.pdf]

23. Shirvanian A, Bakhshoodeh M. Investigating poverty in rural Iran: The multidimensional poverty approach. Agricultural Sciences. 2012; 3(05):640-50.

24. Omidi M, Jani B. Dynamic Poverty Decomposition in Iran's Four Development Plans: Based on New Six-Component Decomposition Method. The Economic Research. 2018; 18(1):179-201.

\section{Figures}

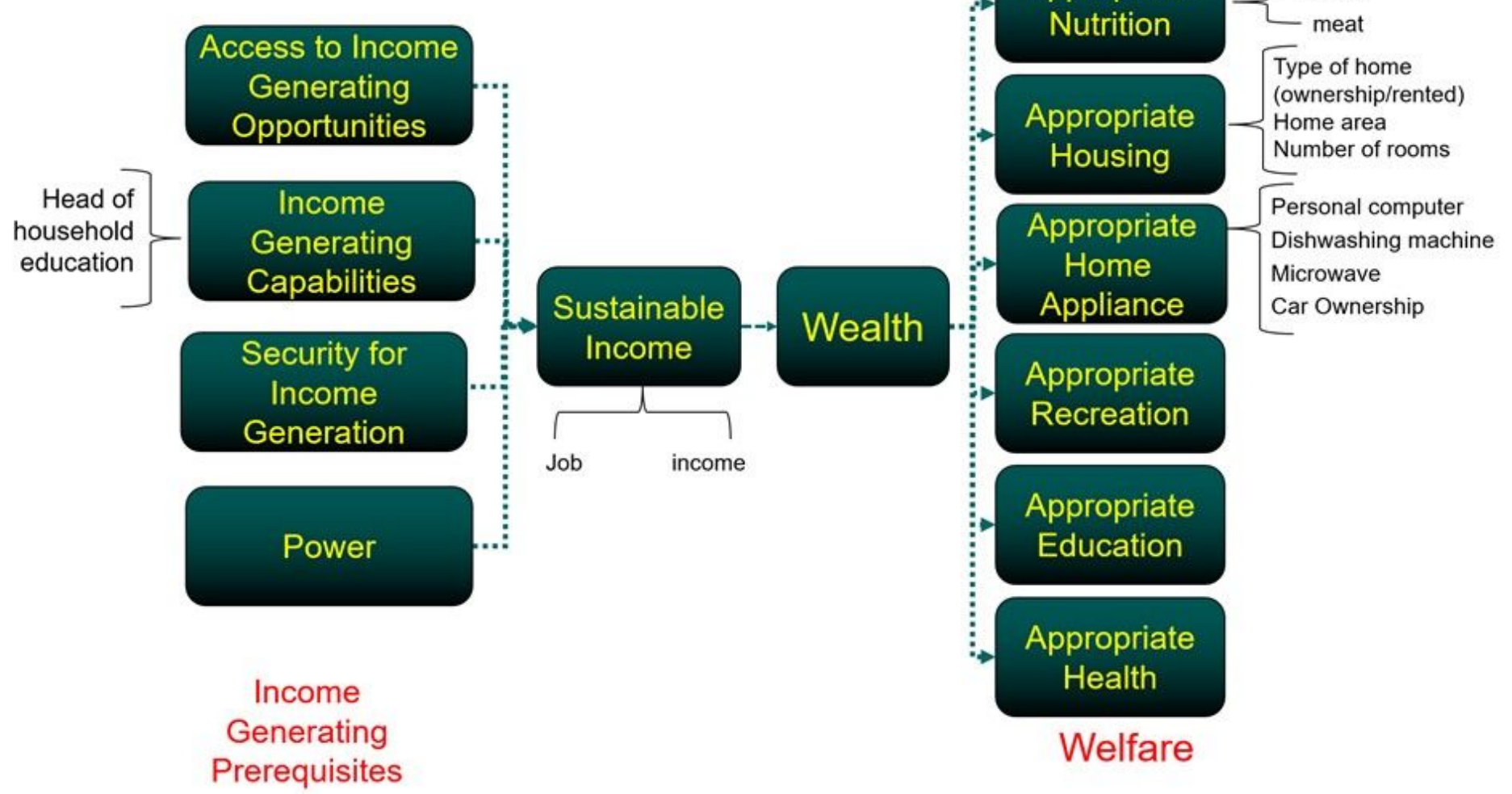

\section{Figure 1}


The Conceptual Model of Wealth and Welfare.

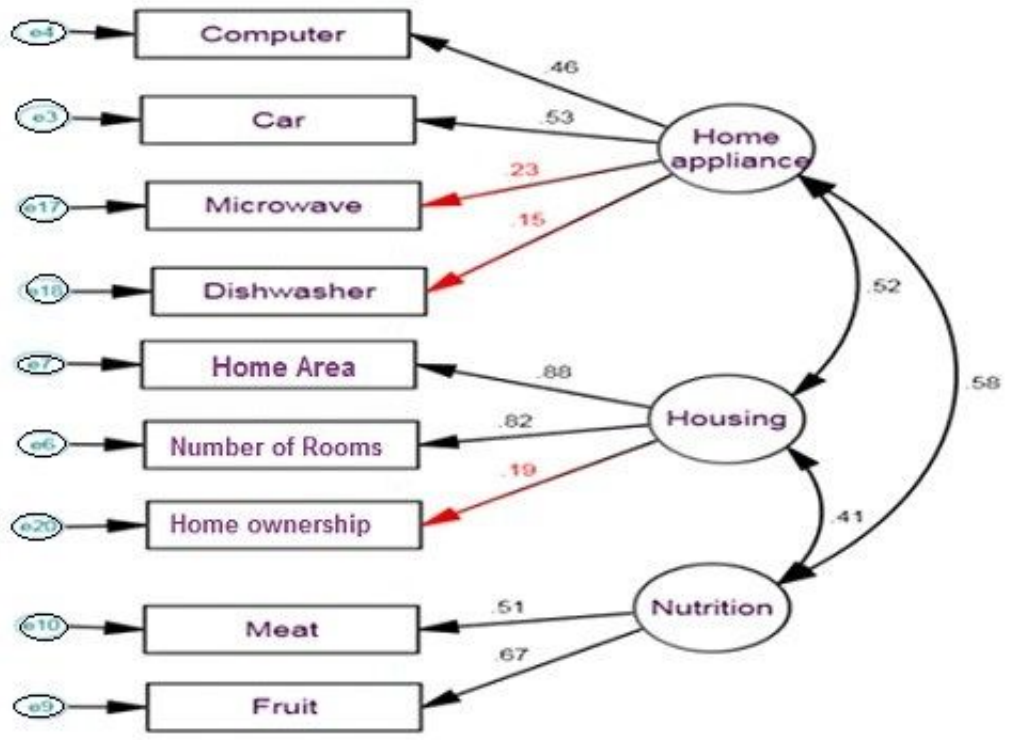

(1) in rural data

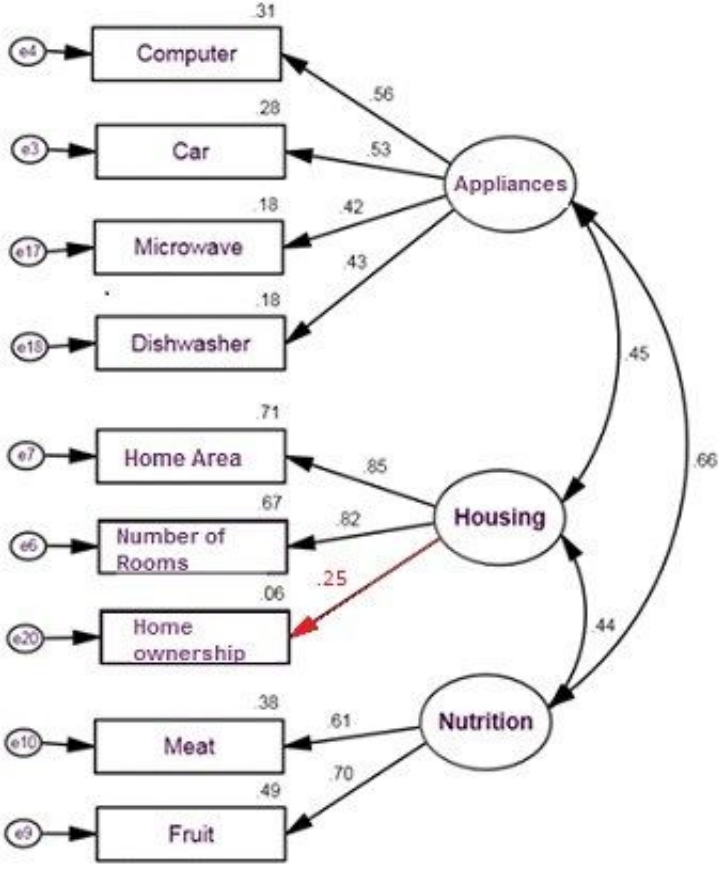

(2) in urban data

Figure 2

Confirmatory Factor Analysis for welfare components in rural \& urban communities. 


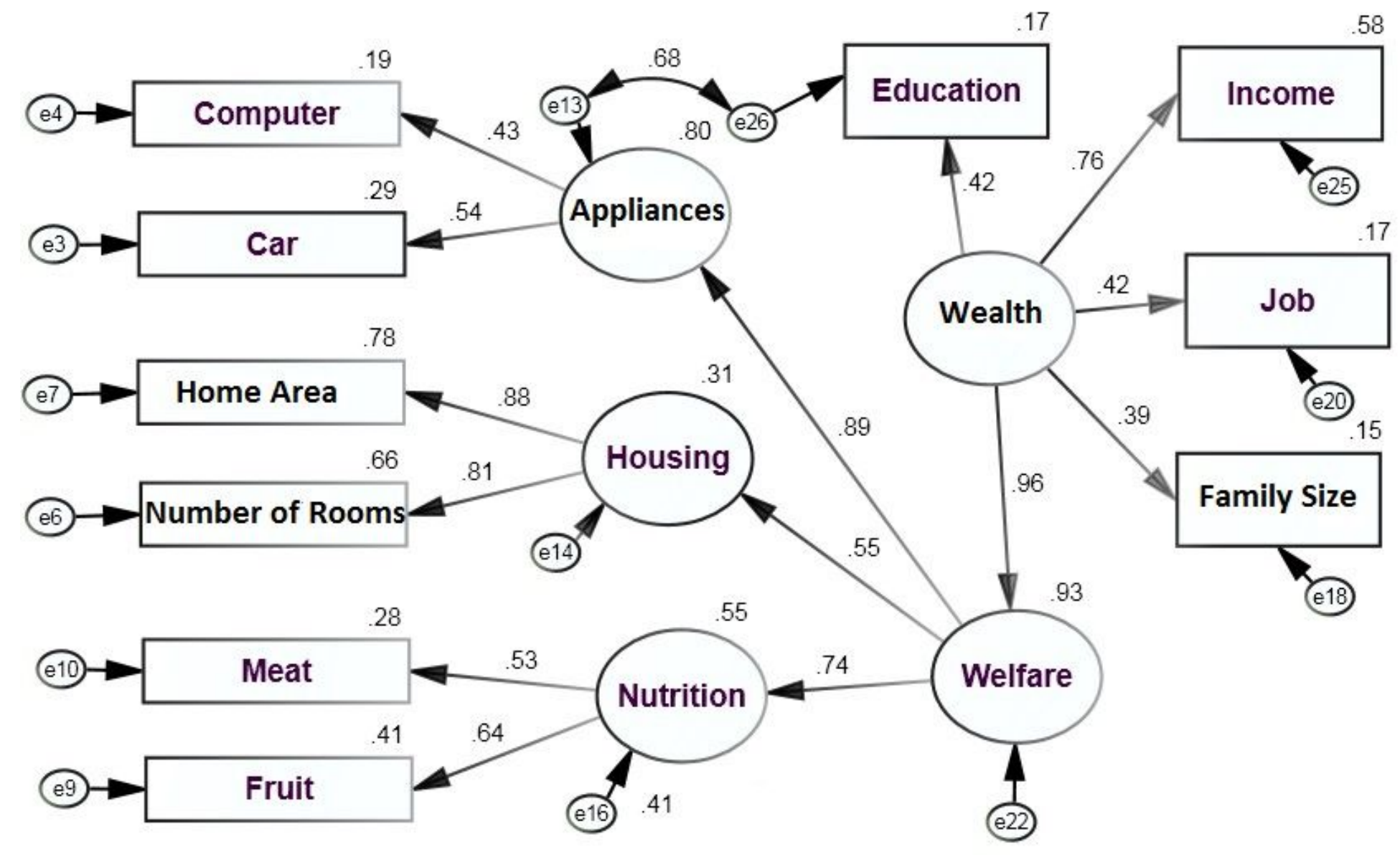

Figure 3

The final model of rural data in Standard Coefficient Estimation Model. 


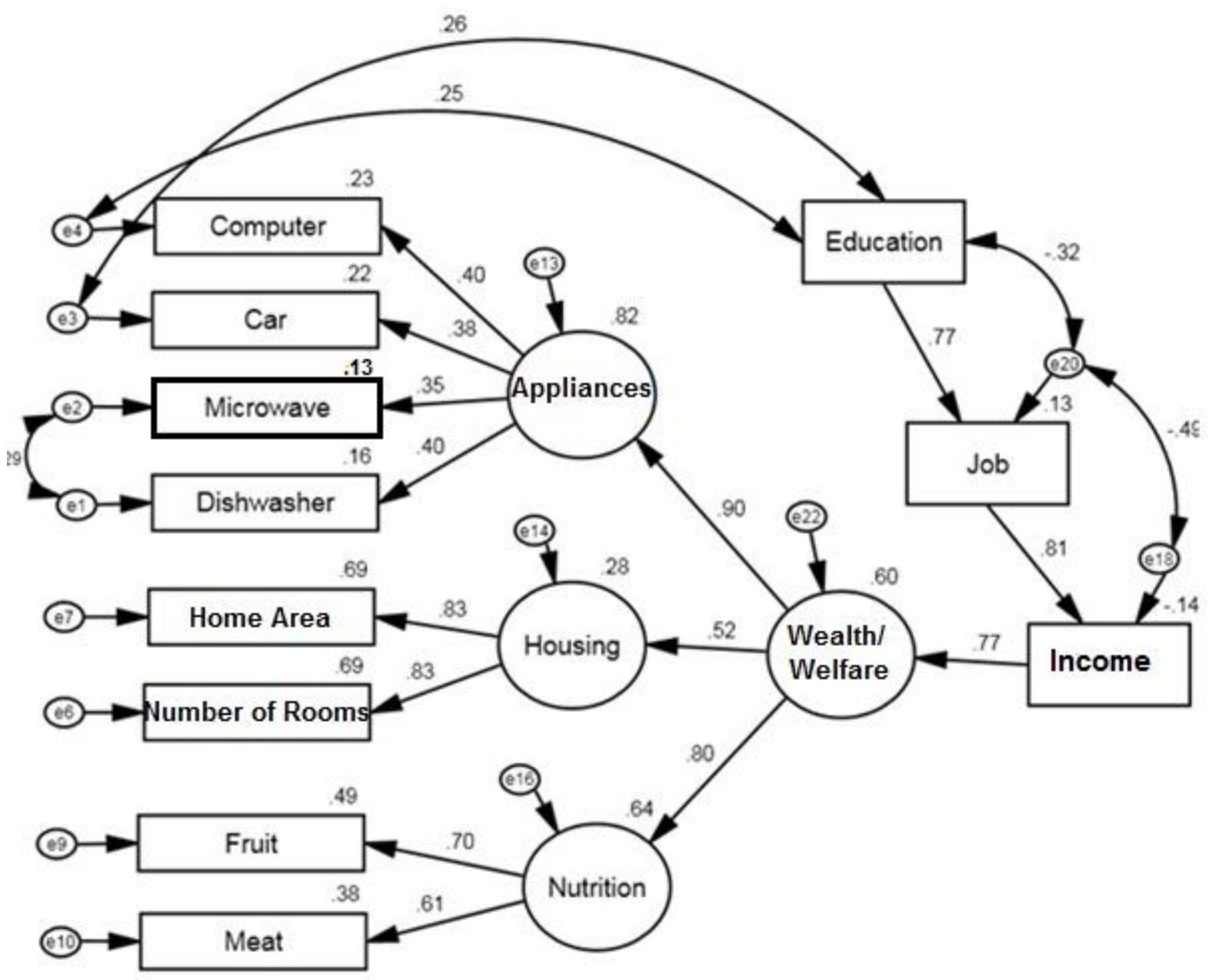

Figure 4

The final model of urban data in standard coefficient estimation model. 